\title{
REFLEXÕES SOBRE A IMPLEMENTAÇÃO DO PROGRAMA DE RESIDÊNCIA PEDAGÓGICA: núcleo de Licenciatura em História do Campus Chapecó da Universidade Federal da Fronteira Sul (UFFS)
}

Introdução

O presente trabalho tem como objetivo apresentar algumas reflexões sobre a implementação do Programa de Residência Pedagógica, mais especificamente o Núcleo de Licenciatura em História do campus Chapecó da Universidade Federal da Fronteira Sul (UFFS). Em um primeiro momento, vamos apresentar brevemente a instituição (e sua vocação para a formação e professores), o curso de Licenciatura em História (e a perspectiva dos Estágios Supervisionados no curso), em seguida, vamos apresentar as duas escolas na quais o projeto do núcleo de História de Chapecó da Residência Pedagógica está presente, a saber: EEB Tancredo de Almeida Neves e a EEB Coronel Ernesto Bertaso.

\footnotetext{
1 Mestre em Educação, professor-assistente da UFFS, coordenador do núcleo do Programa de Residência Pedagógica História, campus Chapecó. Contato: everton. Contato: martins@uffs.edu.br
} 
A Universidade Federal da Fronteira Sul (UFFS) é uma instituição de ensino superior pública que foi criada pela Lei n. 12.029/2009, dentro das ações do Programa de Apoio a Planos de Reestruturação e Expansão das Universidades Federais (REUNI) ${ }^{2}$ (Decreto n. 6.096, de 2007) ${ }^{3}$. A UFFS, atualmente, conta com seis campi ${ }^{4}$ e abrange mais de 400 municípios da Mesorregião da Grande Fronteira do Mercosul - Sudoeste do Paraná, Oeste de Santa Catarina e Noroeste do Rio Grande do Sul. A UFFS conta com seis campi nos três estados da região Sul.

A UFFS desde sua criação tem como um dos focos a formação de professores para a rede básica de ensino. $\mathrm{Na}$ área de licenciaturas, a UFFS foi instituída com onze cursos de licenciatura em seus cinco campi originais. O Projeto Pedagógico Institucional da Universidade Federal da Fronteira Sul tem como um dos princípios norteadores:

Atendimento às diretrizes da Política Nacional de Formação de Professores do Ministério da Educação, estabelecidas pelo

\footnotetext{
2 "Com o Reuni, o governo federal adotou uma série de medidas para retomar o crescimento do ensino superior público, criando condições para que as universidades federais promovam a expansão física, acadêmica e pedagógica da rede federal de educação superior. Os efeitos da iniciativa podem ser percebidos pelos expressivos números da expansão, iniciada em 2003. As ações do programa contemplam o aumento de vagas nos cursos de graduação, a ampliação da oferta de cursos noturnos, a promoção de inovações pedagógicas e o combate à evasão, entre outras metas que têm o propósito de diminuir as desigualdades sociais no país. O Reuni foi instituído pelo Decreto n. 6.096, de 24 de abril de 2007, e é uma das ações que integram o Plano de Desenvolvimento da Educação (PDE)." Este texto está disponível em: http:// reuni.mec.gov.br/o-que-e-o-reuni. Acesso em: 14/10/2019.

3 Art. 2ㅇ O Programa terá as seguintes diretrizes: I - redução das taxas de evasão, ocupação de vagas ociosas e aumento de vagas de ingresso, especialmente no período noturno. (O caso dos cursos de Licenciatura oferecidos pela UFFS) e VI - articulação da graduação com a pós-graduação e da educação superior com a educação básica (Articulação essa, com a Educação Básica na qual o PRP contribui de sobremaneira.

${ }^{4}$ Cerro Largo, RS; Chapecó, SC; Erechim, RS; Laranjeiras do Sul, PR; Passo Fundo, RS; e Realeza, PR.
} 
Decreto n. 6.755, de 29 de janeiro de 2009, cujo principal objetivo é coordenar os esforços de todos os entes federados no sentido de assegurar a formação de docentes para a educação básica em número suficiente e com qualidade adequada. (UFFS, 2012a, p. 14)

Levando-se em consideração a vocação da própria instalação da UFFS, que diz respeito ao atendimento das diretrizes da Política Nacional de Formação de Professores, desde a sua implementação, a UFFS conta com a oferta do curso de Licenciatura em História tanto no campus Erechim, RS, quanto no campus Chapecó, SC. A criação do curso de Licenciatura em História, além do atendimento da demanda da formação docente, também se justifica pela falta de oferta desse curso de forma presencial na região de abrangência da Universidade Federal da Fronteira Sul ${ }^{5}$.

Segundo o Projeto Pedagógico do Curso de Graduação em História - Licenciatura, o objetivo geral do curso é "Formar professores-pesquisadores para atuarem nas mais diversas esferas do ensino e da pesquisa em História” (UFFS, 2012b, p. 25). Sendo que, segundo esse mesmo documento norteador do curso, ao tratar sobre o perfil do egresso,

O licenciado em História deverá ser capaz de atuar como docente na Educação Básica, Ensino Fundamental e Ensino Médio, bem como na pesquisa acadêmica, considerando que o exercício do magistério tem uma dimensão que ultrapassa a mera tarefa pedagógica de transmitir o conhecimento. (UFFS, 2012b, p. 26)

\footnotetext{
5 "Atualmente, no curso de História de Santa Catarina, somente são ofertadas vagas públicas pelas Universidade Federal de Santa Catarina e pela Universidade do Estado de Santa Catarina, sendo os dois cursos na cidade de Florianópolis, que fica a quase 600 km da cidade Chapecó." (UFFS, 2012b, p. 18).
} 
O currículo do curso de Licenciatura em História da UFFS estará organizado em nove semestres, devendo o formando cumprir um número total de no mínimo 2.820 horas entre as oferecidas na matriz curricular do Curso, distribuídas entre componentes curriculares dos domínios comum, conexo e específico, optativas, estágio curricular supervisionado e seminário do trabalho de conclusão de curso. No que diz respeito aos Estágio Curricular Supervisionado, eles são realizados a partir do $4^{\circ}$ semestre do curso e são divididos em Estágio I e II ${ }^{6}, 90$ horas, o equivalente a seis créditos, e está relacionado à experiência no Ensino Fundamental (Anos Finais); e em Estágio III e IV ${ }^{7}, 120$ horas, o equivalente a oito créditos, e está relacionado à experiência no Ensino Médio. Nesse contexto, “[...] o Estágio Curricular Supervisionado em História caracteriza-se pela produção de conhecimentos, elaboração de estratégias de ensino e pela prática efetiva de intervenção docente em ambientes escolares.” (UFFS, 2012b, p. 26).

\footnotetext{
${ }^{6}$ Ementa: "Fundamentação teórica e metodológica para a realização de pesquisa de campo didático-histórica e para a formulação de projetos em Ensino de História no ensino fundamental. Pesquisa de campo didático-histórica nos dois últimos ciclos do ensino fundamental ( $6^{\circ}$ ao $9^{\circ}$ ano). Os parâmetros e diretrizes para a disciplina de História em nível fundamental. Os materiais didáticos para o ensino fundamental. Realização de pesquisa de campo didático-histórica. Elaboração de projeto de pesquisa e intervenção em Didática da História. Elaboração de relatório de estágio". Objetivo: 'Preparar os discentes para a realização de pesquisa de campo e para o exercício das práticas docentes em Ensino de História no ensino fundamental" (UFFS, 2012b).

7 Ementa: "Fundamentação teórica e metodológica para a realização de pesquisa de campo didático-histórica e para a formulação de projetos em Ensino de História no ensino médio. Pesquisa de campo didático-histórica no ensino médio. Os parâmetros e diretrizes para a disciplina de História em nível médio. Os materiais didáticos para o ensino médio. Realização de pesquisa de campo didático-histórica. Elaboração de projeto de pesquisa e intervenção em Didática da História. Elaboração de relatório de estágio". Objetivo: Preparar os graduandos para a elaboração de projetos de pesquisa e intervenção e para planejamento de práticas de intervenção docente em Ensino de História no ensino médio. (UFFS, 2012b).
} 
O Estágio Curricular Supervisionado é considerado parte importante na formação dos futuros licenciados em História, dessa forma, o Projeto Pedagógico do Curso prevê que “[...] o Estágio Curricular Supervisionado em História é atividade obrigatória, que privilegia a formação integral do profissional de História, com desenvolvimento de atividades de ensino, pesquisa e extensão." (UFFS, 2012b, p. 170). Assim sendo, o espaço dos estágios não é percebido como um momento estanque, mas sim como um espaço privilegiado de articulação entre os componentes curriculares, embora não só como um espaço importante para a articulação entre ensino, pesquisa e extensão, porém, mais que isso, o Projeto Pedagógico do Curso prevê que

O Estágio Curricular Supervisionado em História caracteriza-se pela produção de conhecimentos, elaboração de estratégias de ensino e pela prática efetiva de intervenção docente em ambientes escolares. (UFFS, 2012b, p. 170)

Conforme Delgado (2011, p. 221), a vivência no período do estágio supervisionado de História é um marco na trajetória profissional dos graduandos, visto que, para muitos, é a primeira experiência em sala de aula com a visão docente.

A normativa reguladora do estágio prevê que a prática é um ato educativo escolar supervisionado, desenvolvido no ambiente de trabalho, que visa à preparação para o trabalho produtivo de educandos que estejam frequentando o ensino regular em instituições de educação superior, de educação profissional, de ensino médio, de educação especial e dos anos finais do ensino fundamental, na modalidade profissional da educação de jovens e adultos (LEI n. 11.788, de 25 de setembro de 2008). Assim, o estágio funciona como uma experimentação das futuras atividades de um docente em um espaço escolar, seja ele na educação regular, profissionalizante ou de jovens e adultos. 
Tendo em vista a importância dos Estágios Curriculares Supervisionados, no ano de 2018, o colegiado do curso de Licenciatura em história do campus Chapecó dedicou-se a debater a adesão do curso ao Programa de Residência Pedagógica. Segundo a Portaria GAB n. 38, de 28 de fevereiro de 2018, a Capes, que institui o Programa de Residência Pedagógica, tem como objetivo:

Aperfeiçoar a formação dos discentes dos cursos de licenciatura, por meio do desenvolvimento de projetos que fortaleçam o campo da prática e que conduzam o licenciando a exercitar de forma ativa a relação entre teoria e prática profissional docente, utilizando coleta de dados e diagnóstico sobre o ensino e a aprendizagem escolar, entre outras didáticas e metodologias; II. Induzir a reformulação do estágio supervisionado nos cursos de licenciatura, tendo por base a experiência da residência pedagógica; III. Fortalecer, ampliar e consolidar a relação entre a IES e a escola, promovendo sinergia entre a entidade que forma e aquelas que receberão os egressos das licenciaturas, além de estimular o protagonismo das redes de ensino na formação de professores; e IV. Promover a adequação dos currículos e das propostas pedagógicas dos cursos de formação inicial de professores da educação básica às orientações da Base Nacional Comum Curricular (BNCC). (BRASIL, 2018)

A Residência Pedagógica como projeto constituído pela Coordenação de Aperfeiçoamento de Pessoal de Ensino Superior (CAPES) prevê na sua proposta que os professores residentes frequentem um centro de excelência da educação básica no qual realizam atividades teórico-metodológicas como fundamento do conceito de "imersão" e de parceria na atividade prática entre diferentes instituições. Sendo assim, o programa não se limita somente à vivência em sala de aula, mas busca constituir uma interação entre pesquisa acadêmica e teoria-prática docente (SILVA; CRUZ, 2018, p. 236). 
Em um primeiro momento, ocorreu um debate entre os membros do Colegiado do Curso de História ${ }^{8}$, que gerou uma grande apreensão em aderir ao PRP, por receio de descaracterizar os Estágios do Curso; de uma possível falta de demanda por parte dos acadêmicos e/ou por receio de a PRP servir unicamente para a implementação da BNCC sem qualquer debate. Após debates e estudos de demandas, o Colegiado decidiu aderir ao PRP e criar um núcleo no campus de Chapecó, tendo em vista a demanda apresentada. Assim, o PRP vem para contribuir nas dinâmicas dos Estágios Supervisionados. Dessa forma, os acadêmicos ao se matricularem nos Estágios Supervisionados, podem participar como bolsistas do PRP ou não. Contudo, cabe destacar que as ações são em paralelo, buscando desenvolver uma formação que, enfim, seja de caráter emancipador (SILVA; CRUZ, 2018). Percebe-se aqui na conjunção entre os Estágios Supervisionados e a Residência pedagógica um espaço de reflexão e ação, uma ação coordenada entre universidade e escola, entre orientador-receptor-residente, pois, caso contrário, percebe-se que o estágio;

[...] reduz-se a observar os professores em aula e imitar os modelos, sem proceder a uma análise crítica fundamentada teoricamente e legitimada na realidade social em que o ensino se processo. Assim, a observação, se limita à sala de aula, sem análise do contexto escolar, e espera-se do estagiário a elaboração e execução de "aulas-modelo". (PIMENTA; LIMA, 2004, p. 36)

Buscando romper com essa lógica apresentada por Pimenta e Lima (2004), buscou-se pesar o PRP. De acordo com Schmidt e Cainelli (2004, p. 33), a metodologia do ensino de História baseada na repetição dos conteúdos, utilizada pela prática docente como se

${ }^{8}$ O colegiado de Curso é considerado o órgão máximo do curso e é composto de representantes dos docentes, discentes e Técnicos-Administrativos em Educação do curso. 
o "professor fosse uma enciclopédia", detentor do saber, foi sendo substituída por uma nova forma de pensar o ensino de História. A prática docente deve se empenhar na construção e no compartilhamento de conteúdo por professores e alunos, então, o professor de História será responsável por ajudar o aluno a aprender a pensar historicamente, oferecendo condições para que ele participe do processo de construção do conhecimento histórico.

Dessa forma, o objetivo geral do PRP na UFFS é fortalecer e qualificar o trabalho de Estágio Curricular Supervisionado, por meio de estudos pertinentes ao exercício da docência, da imersão coletivamente planejada e sistemática do aluno de licenciatura visando a promover a vivência e a experimentação de situações concretas do cotidiano escolar, da sala de aula e do estreitamento permanente da relação entre os Cursos de Licenciatura da UFFS e a Educação Básica. Além disso, cabe ressaltar que no caso do Estado de Santa Catarina, o Programa de Residência Pedagógica vai ao encontro da sétima meta do Plano Estadual de Educação que prevê uma melhoria na qualidade da educação básica a partir da seguinte estratégia: estimular a articulação entre a graduação, a pós-graduação, os núcleos de pesquisa e de extensão e os cursos de formação continuada para profissionais da educação básica, de modo a garantir a elaboração de currículos e de propostas pedagógicas que incorporem os avanços de pesquisas ligadas ao processo de ensino-aprendizagem e às teorias educacionais (SANTA CATARINA, 2014, p. 119).

Nesse contexto, devemos refletir sobre o papel da escola, apontado por Martins (2009, p. 11.165), quando ele afirma que:

[...] servir como um espaço de aprendizagem prática para o dia a dia, e não apenas um espaço para repassar conhecimentos fragmentados, que em muitos momentos parecem ser sem qualquer valia para a vida profissional e pessoal dos que este ambiente frequentam, com o objetivo de acrescentar algo a mais do que um certificado de conclusão do Ensino Médio em suas vidas. 
Aqui cabe refletir sobre o assunto tratado, partindo das contribuições de Schmidt e Cainelli (2004), quando alertam que tanto os docentes quanto os discentes devem ser tratados como sujeitos da história e da produção do conhecimento histórico, e como sujeitos produtores da história, e não apenas como receptores passivos e espectadores de uma história de heróis e de personagens dos livros didáticos. É importante que exerçamos um exercício de reflexão acerca dos conteúdos presentes nesses materiais didáticos e utilizemos nossa capacidade intelectual e nosso conhecimento da área para analisar se o que está presente ali é de fato plausível e verídico e se, de alguma forma, não fará mal para os alunos que, porventura, vierem a se identificar com os indivíduos presentes naquele conteúdo.

Levando-se em conta tais reflexões, o projeto institucional intitulado "Residência Pedagógica: uma estratégia de fortalecimento e qualificação do Estágio Curricular Supervisionado na UFFS" abrangeu oito Subprojetos, em um total de 15 núcleos. Há, pelo menos, sete princípios articuladores desses subprojetos com o projeto institucional:

1 - A docência como atividade profissional intencional e metódica; 2 - O currículo como produto e como processo histórico; 3 - O conhecimento como práxis social; 4 - A formação Integral e a processualidade dialógica na organização pedagógica; 5 - A gestão democrática e o planejamento participativo; 6 - A articulação com a educação básica pública; 7 - O egresso (residente) como docente da educação básica pública. (Residência Pedagógica: uma estratégia de fortalecimento e qualificação do Estágio Curricular Supervisionado na UFFS, 2018, p. 1)

O núcleo de Licenciatura em História do campus Chapecó, o PRP, foi organizado para ter 24 bolsistas remunerados, seis bolsistas voluntários (sendo que apenas uma vaga foi preenchida), três preceptoras e um orientador. O projeto está presente em duas escolas 
do município de Chapecó, a saber: EEB Tancredo de Almeida Neves (dois grupos com duas preceptoras e oito bolsistas remunerados e um bolsista voluntária); e a EEB Coronel Ernesto Bertaso (uma preceptora e oito bolsistas remunerados). Apresentar emosde forma mais adequada as escolas nas próximas estapas do texto.

No núcleo de Licenciatura em História do campus Chapecó, a dinâmica do acompanhamento pelo docente orientador e pelo preceptor vem ocorrendo a partir de fichas de controle disponibilizadas pela coordenação institucional do PRP da UFFS, além de contar com reuniões entre todos os envolvidos no programa. Durante a realização do PRP, foram reservados espaços no momento inicial do programa para preparação dos alunos e a participação deles no programa, além de momentos dedicados para orientação conjunta (coordenador/supervisor), ambientação do residente na escola e preparação do Plano de Atividade da residência, assim como imersão na Escola, contendo no mínimo 100 horas de regência de classe, produção do relatório final e, após, espaço para avaliação e socialização dos resultados.

Levando-se em conta a articulação entre as atividades previstas no PPC dos cursos e o PRP, ao longo do desenvolvimento das atividades da PRP, buscou-se dar especial atenção à fundamentação teórica e metodológica para a realização de pesquisa de campo didático-histórica e para a formulação de projetos em Ensino de História no ensino fundamental e no ensino médio, além de pesquisa de campo didático-histórica nos dois últimos ciclos do ensino fundamental ( $6^{\circ}$ ao $9^{\circ}$ ano) e para o Ensino Médio. Conjugada as ações citadas anteriormente, as ações da Residência Pedagógica prevêm a construção de materiais didáticos para o ensino fundamental e médio e a realização de pesquisa de campo didático-histórica. Elaboração de projeto de pesquisa e intervenção em Didática da História. Elaboração de relatório de estágio, e, por fim, a prática de ensino supervisionada nas escolas. 
A Residência Pedagógica consiste na imersão planejada e sistemática do aluno de licenciatura em ambiente escolar, visando à vivência e à experimentação de situações concretas do cotidiano escolar e da sala de aula, que, depois, servirão de objeto de reflexão sobre a articulação entre teoria e prática. Durante e após a imersão, o residente deve ser estimulado a refletir sobre sua prática e a avaliar a relação com a profissionalização do docente escolar, para registro em relatório, contribuindo parea a avaliação de socialização de sua experiência como residente. Esse material deverá ser utilizado pela IES para inovar o estágio curricular de seus cursos de licenciatura, pois entendemos que o estágio se constitui como um campo de conhecimento, o que significa atribuir-lhe um estatuto epistemológico que supera sua tradicional redução à atividade prática instrumental. Como campo de conhecimento, o estágio se produz na interação dos cursos de formação com o campo social no qual se desenvolvem as práticas educativas, o que é catalisado pelo PRP que é compreendido como um tempo-espaço de formação teórico-prática orientada e supervisionada, que mobiliza um conjunto de saberes acadêmicos e profissionais para observar, analisar e interpretar práticas institucionais e profissionais e/ou para propor intervenções para o fortalecimento e a qualificação das reflexões acadêmico-profissionais, de iniciação à pesquisa, de reconhecimento do campo de atuação profissional e de redimensionamento dos projetos de formação inicial de professores, respeitando a trajetória e a especificidade do curso e suas bases teórico-conceituais, epistêmicas e metodológicas.

O primeiro semestre da Residência Pedagógica (2018.2) serviu para o diagnóstico da realidade escolar e do Projeto Político Pedagógico da Escola-Campo, foi elaborado diagnóstico a respeito das escolas-campo, contribuindo na revisão dos PPPs das Escolas e na qualificação da abordagem dos conhecimentos escolares na relação com a realidade dos alunos, da escola e da comunidade. Somado a 
isso, foram produzidos, em conjunto, os Planos de intervenção dos residentes, elaborando os planos de trabalho que visem a proporcionar as vivências laboratoriais, a produção de sequências didáticas, os planos de ensino, os projetos multidisciplinares, com o intuito de organizar e de participar de atividades culturais e/ou feiras do conhecimento proporcionadas pela escola. Além de estudos da BNCC e seus desdobramentos na organização do plano de trabalho docente e do plano de aula, somada à leitura/estudo dirigido da BNCC. Tal ação teve por objetivo potencializar reflexões acerca das relações entre BNCC, os conhecimentos específicos de cada área do conhecimento e o diagnóstico da realidade escolar.

Após apresentar brevemente nossa instituição (e sua vocação para a formação de professores), o curso de Licenciatura em História (e a perspectiva dos Estágios Supervisionados no curso), vamos apresentar duas escolas na quais o projeto do núcleo de História de Chapecó está presente, a saber: EEB Tancredo de Almeida Neves e a EEB Coronel Ernesto Bertaso.

\section{A Escola de Educação Básica Coronel Ernesto Bertaso}

Escola de Educação Básica Coronel Ernesto Bertaso está situada na Rua Castro Alves, Bairro São Cristóvão, na cidade de Chapecó, Estado de Santa Catarina. O bairro São Cristóvão abrange cerca de 16\% da população de 183 mil habitantes (IBGE, 2010) e se constitui ao longo das indústrias Cooperativa Central Aurora Alimentos e Cooperativa Agroindustrial Alfa, que estão nos limites Leste do bairro próximo ao centro da cidade e moldam a dinâmica em que o bairro se organizou, influenciando na sua organização cultural. A região em que a escola se insere é marcada por indústrias, logo, os estudantes são em sua maioria filhos desses trabalhadores, o bairro 
se situa próximo ao centro da cidade. A escola foi fundada no ano de 1960 em um terreno doado pela Empresa Bertaso Ltda. ${ }^{9}$ Em 1960, ano de sua fundação, a escola funcionou em uma única sala de aula, como extensão da E.E.B. Marechal Bormann. Em 1961, já no terreno doado, passou a ser denominada Escola Reunida José Motta Pires e, em 1966, passou a ser Ginásio Escolar Ernesto Bertaso, contando com apenas três salas de aula. No ano de 1973, foi autorizado o funcionamento da $5^{\mathrm{a}}$ série do ensino fundamental e, assim, sucessivamente até a $8^{\text {a }}$ série. Em 1974, foi inaugurado o prédio onde se encontra a escola atualmente. Em 1985, foi transformada em Escola Básica e autorizado o funcionamento do Ensino Médio.

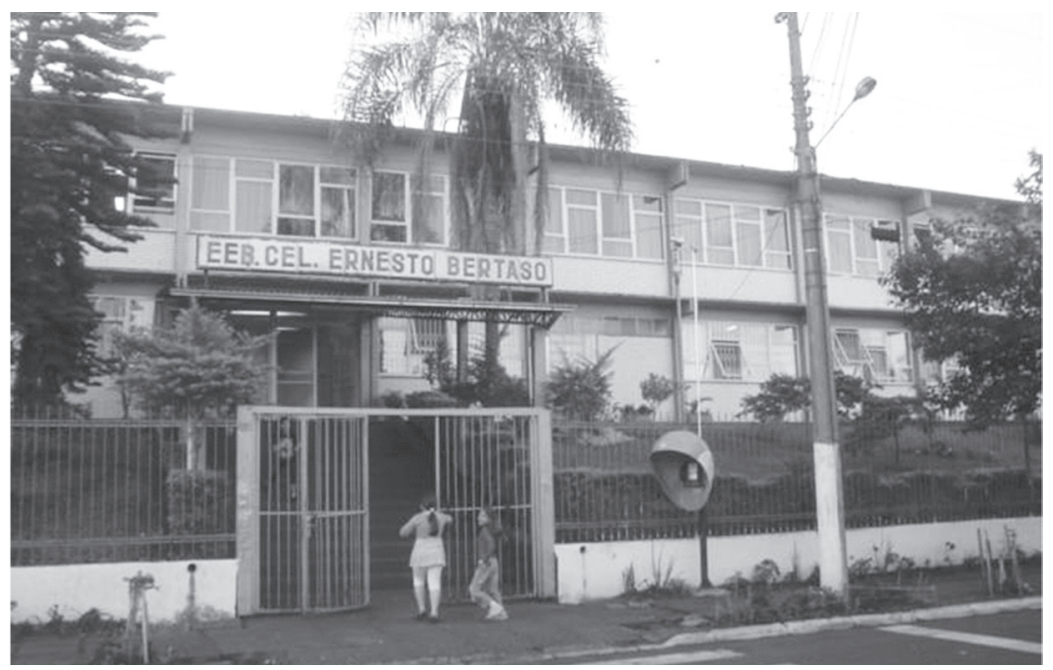

Figura 1 - Fachada da EEB Ernesto Bertaso.

Fonte: Acervo Pessoal do autor deste capítulo

9 A Empresa foi uma das primeiras colonizadoras de Chapecó, fundada por Ernesto Francisco Bertaso e os irmãos Agilberto Atílio e Manoel dos Passos Maia, em 1918, e se instalou no antigo povoado de Passo dos Índios (atual cidade de Chapecó) com um escritório. Essa colonizadora tornou-se proprietária de vasta área e responsável por qualquer iniciativa comercial e colonizadora dentro de seu patrimônio. 
No ano de 2017, foi implementado na escola o Ensino Médio Integral em Tempo Integral (EMITI), sob regência do Instituto Ayrton Senna, que toma o Ensino Integral como chave para preparar as novas gerações para viver no século XXI.

Acrescentamos ainda o perfil dos discentes, pois, segundo o Plano Político Pedagógico (PPP) da instituição, a "[...] maioria dos alunos da escola mora no Bairro São Cristóvão que é formado pela classe operária das agroindústrias, moveleiras, pequenas empresas, prestação de serviços" (E.E.B. CEL. ERNESTO BERTASO, 2017, p. 4). A percepção de alunos oriundos de "classes operárias" pode ser creditada à filiação filosófica explicitada no PPP, o materialismo histórico-dialético, definindo que, a partir dessa perspectiva, a escola tenha a "[...] função de entender o homem como um ser social e histórico" (E.E.B. CEL. ERNESTO BERTASO, 2017, p. 4). A apresentação do contexto social da escola e dos indivíduos que dela participam é também aspecto relevante para problematizar diversos aspectos que são inerentes ao processo educacional e que, por vezes, permanecem silenciados pelos enfoques teóricos desconectados da realidade observada, o objetivo da unidade é "[...] a formação de um aluno crítico, autônomo e participativo" (E.E.B. CEL. ERNESTO BERTASO, 2017, p. 3).

A unidade escolar E.E.B. Cel. Ernesto Bertaso é um prédio de dois pisos com duas entradas, a principal com escadaria, sem acessibilidade, e a outra secundária sem escadas, "[...] podendo dar acessos aos portadores de necessidades especiais (apenas $1^{\circ}$ piso) (E.E.B. CEL. ERNESTO BERTASO, 2017, p. 18). Possui uma extensão de 6 mil metros quadrados, cercado por muros e grades, contém 2.200 metros quadrados construídos, disponibiliza 13 salas no total, sendo que 11 se encontram no segundo piso do prédio, e as outras na parte do primeiro piso, além de também se encontrar na parte inferior, a secretária, a sala da direção, a sala dos professores, a sala da coordenação pedagógica, a sala de Atendimento Educacional Especializado 
(AEE), o depósito de materiais de limpeza, a área de serviço, o refeitório, a cozinha dos alunos (sendo as refeições terceirizadas), a cozinha dos professores, os banheiros femininos e masculinos e os banheiros dos professores. A escola também conta com uma biblioteca localizada ao lado externo do prédio.

Um dos diferenciais da E.E.B. Cel. Ernesto Bertaso é que ela aderiu ao Ensino Médio Inovador. Tal adesão se deu em parceria com o Instituto Ayrton Senna. O programa surgiu pela necessidade de ressignificar o ensino médio na perspectiva de possibilitar o acesso, o progresso e as aprendizagens esperadas para adolescentes de 15 a 17 anos nessa etapa da educação básica, de forma a atender às metas do Plano Nacional de Educação (PNE) e a Lei n. 13.005/2014. A proposta pedagógica teve por base a ampliação da jornada escolar e a formação integral e integrada dos estudantes, tanto nos aspectos cognitivos quanto nos aspectos socioemocionais, de acordo com os quatro pilares da educação: aprender a conhecer, a fazer, a conviver e a ser. A partir desse programa, a Secretaria de Estado da Educação de Santa Catarina propôs um redesenho curricular pautado no conceito de educação integral, no protagonismo juvenil, em uma matriz para desenvolvimento de competências para o século XXI e estratégias de organização integradas e flexíveis para o currículo. Para que esses conceitos chegassem até os estudantes, trilhou-se um caminho formativo com as práticas dos gestores e dos professores para que os resultados fossem apurados e a implementação do programa pudesse ser avaliada continuamente, no sentido de manter o alinhamento das ações sempre que necessário. Todo esse processo visa à institucionalização do programa na rede e a expansão ano a ano (SED, 2017, p. 8). Tais perspectivas estão em consonância com o PPP da escola quando afirma que:

A educação deve ser de boa qualidade, com relativo poder de transformação social, que contribua para construção de uma 
sociedade que preze pela inclusão humana transformadora, para ser justa democrática, solidária, coletiva, crítica e consciente, participativa, ativa e que valorize o ser, instrumentalizando os alunos pelo conhecimento científico para exercer sua cidadania. (E.E.B. CEL. ERNESTO BERTASO, 2017, p. 4)

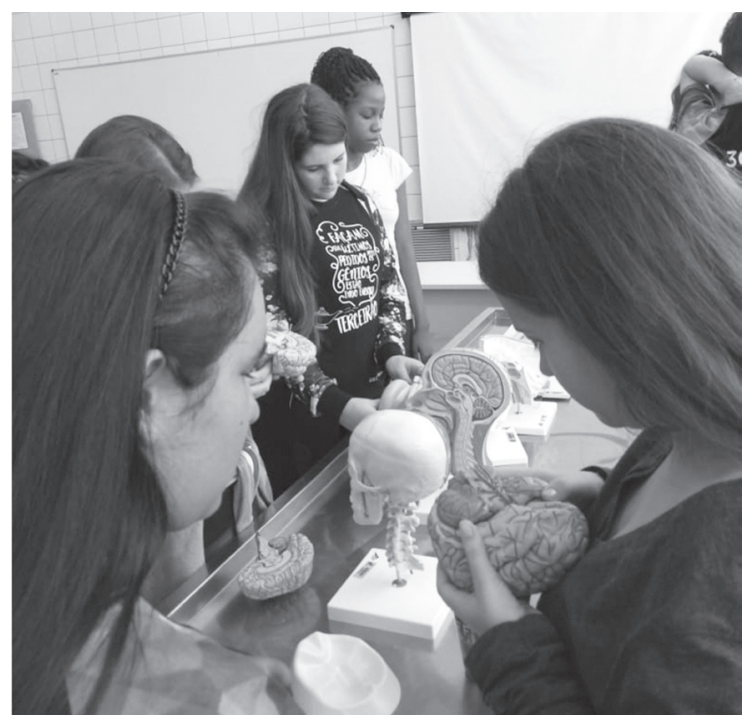

Figura 2 - Visita ao laboratório e Anatomia da UFFS da turma de $3^{\circ}$ ano do Ensino Médio da E.E.B. Cel. Ernesto Bertaso Fonte: Imagem de Eliriane Ana Tonatto dos Santos

Dentro dessa perspectiva, os residentes em conjunto com a preceptora e o docente orientador buscaram ações que contribuíssem com o projeto pedagógico da escola e com as perspectivas do EMI. Tendo em vista a carga horária ampliada do Ensino Médio, foi possível desenvolver ações com maior duração, aproveitando a colaboração de todos os professores da escola, optou-se por trabalhar em alguns momentos com projetos de intervenção, em que a turma passava um período (matutino ou vespertino) todo com os residentes e 
eram tratadas temáticas previamente definidas e organizadas. Além disso, foi possível, graças ao PRP e à disponibilização de recursos da UFFS, a visita guiada da turma de $3^{\circ}$ ano do Ensino Médio ao campus da UFFS em Chapecó, como atividade de conclusão da intervenção no primeiro semestre de 2019.

\section{A Escola de Educação Básica Tancredo de Almeida Neves}

A E.E.B. Tancredo de Almeida Neves está localizada no Bairro EFAPI, local em que estão inseridas duas universidades: a UFFS e a Unochapecó, além de empresas da agroindústria, do comércio diverso, do posto de saúde, da delegacia policial, do posto de polícia militar e da penitenciária agrícola. A escola é a única da rede estadual que oferta Ensino Médio na região.

Como consta no Projeto Político Pedagógico (PPP), a escola possui uma estrutura física bastante ampla, com um terreno de $7.259,54 \mathrm{~m}^{2}$ e uma área construída de primeiro piso de $14.446,10$ metros quadrados; segundo piso de 1.404,10 metros quadrados e ginásio de 1.150,00 metros quadrados. A escola possui 13 salas de aula, quatro laboratórios (Biologia, Física, Matemática e Química), dois Laboratórios de Informática, uma sala de Artes, uma sala de Violão, uma sala de Percussão, uma sala para o SAEDE, uma sala do antigo PENOA, Cozinha, Refeitório, três conjuntos de sanitários, Biblioteca, Secretaria, sala Pedagógica, sala de Professores e sala de Direção. Anexo à Escola há um Ginásio Poliesportivo. A biblioteca é ampla, arejada, com acervo razoável, mas não possui bibliotecário/a. O espaço administrativo é apropriado. As salas de aula são insuficientes, com problemas de manutenção, assim como os sanitários. As salas de laboratórios e as salas de tecnologias são apropriadas, mas não possuem equipamentos e instrumentos suficientes, além de ter custo 
de manutenção muito alto, impossibilitando a renovação ou aquisição de outros instrumentos. As condições de acessibilidade são condizentes com as regras da ABNT e segundo as vistorias anualmente feitas na escola (E.E.B. TANCREDO NEVES, 2018, p. 77)

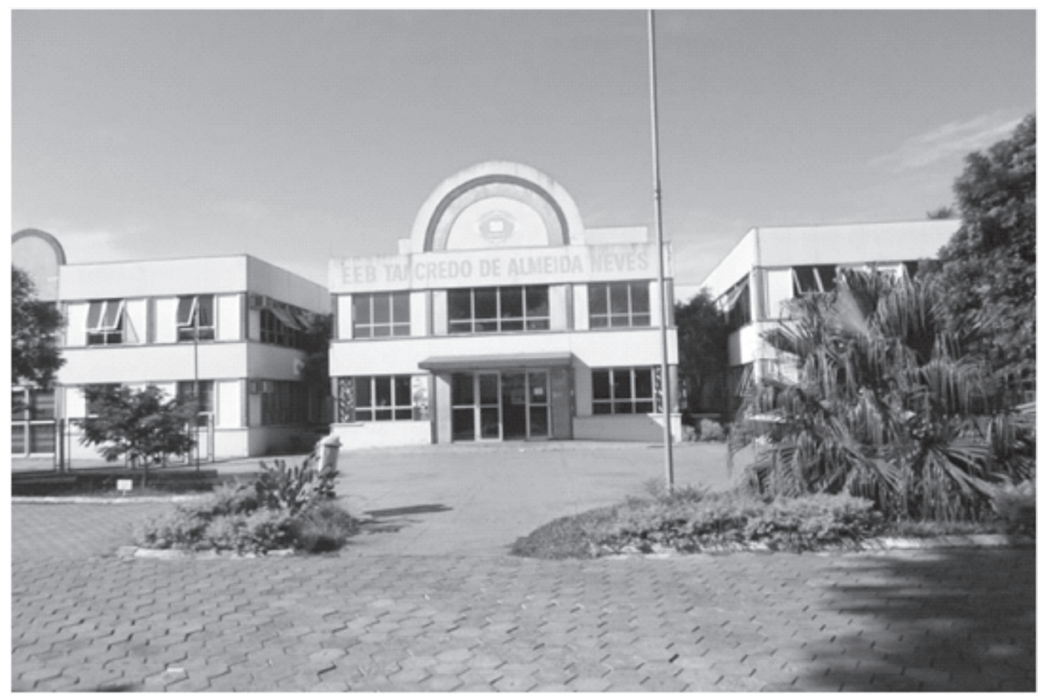

Figura 3 - Fachada da E.E.B. Tancredo Neves

Fonte: Imagem de André Luiz Paz e Thais Gandolfi

A partir do PPP, é possível perceber que uma parcela significativa dos alunos advém de famílias de classe baixa e média, cujos pais, em sua maioria, não conseguiram completar o Ensino Médio. Isso pode ser entendido, por um lado, pelo fato de que apenas em 1996 o bairro Efapi conseguiu obter uma escola que ofertasse Ensino Médio, sendo essa escola a própria E.E.B. Tancredo de Almeida Neves. Antes disso, na década de 1980, só era oferecido o ensino de $1^{\text {a }}$ a $4^{\text {a }}$ série, dessa forma, as famílias que tinham condições de pagar o transporte, enviavam seus filhos para estudar em escolas de outros bairros, sendo importante lembrar que, na época, nem 
todos conseguiam arcar com essa despesa, o que explica o motivo de uma parcela significativa de pais não terem conseguido terminar o Ensino Médio. Foi por meio das reivindicações da comunidade que o bairro Efapi conseguiu criar e ampliar suas escolas e oferecer um ensino mais acessível para os seus habitantes, o que resultou, em parte, em uma escola engajada com seu contexto e com a população que a construiu. De acordo com o PPP da escola, os alunos que frequentam a E.E.B. Tancredo de Almeida Neves, em sua maioria, compõem a classe baixa e média da sociedade, são moradores dos arredores da escola e a maior porcentagem dos pais possuem, no máximo, a formação completa no Ensino Médio, como é apresentado. A Renda Familiar de 48,5\% é de um a dois salários mínimos; 24,5\% é de três a quatro salários mínimos; $15 \%$ é acima de quatro salários mínimos; $12 \%$ é de até um salário mínimo. O Grau de escolaridade do pai; $25 \%$ Ensino Fundamental completo ( $1^{\circ}$ a $4^{\circ}$ ano); $18 \%$ Ensino Fundamental completo ( $5^{\circ}$ a $8^{\circ}$ ano); $12,5 \%$ Ensino Fundamental incompleto ( $5^{\circ}$ a $\left.8^{\circ}\right) ; 21 \%$ Ensino Médio completo; $13,5 \%$ Ensino Médio incompleto; 1,5\% Ensino Superior (cursando); 8,5\% Ensino Superior completo (E.E.B. TANCREDO NEVES, 2018, p. 5).

Apesar da insuficiência de salas, a escola adotou a utilização de salas ambientes, em que os alunos trocam de sala de acordo com seus horários e as disciplinas que estudam no dia. Essa iniciativa mostra-se satisfatória nesta unidade escolar, visto que tanto os professores quanto os alunos integram-se melhor ao ambiente por terem a liberdade de organizarem suas salas de acordo com a disciplina trabalhada. Assim, os professores e os alunos podem pintar as paredes e decorarem as portas das salas de acordo com a disciplina, não ficando condicionados à divisão do espaço com as demais. Na sala de História que foi observada, existe em uma das paredes diversas pinturas que representam personagens e tempos históricos. 


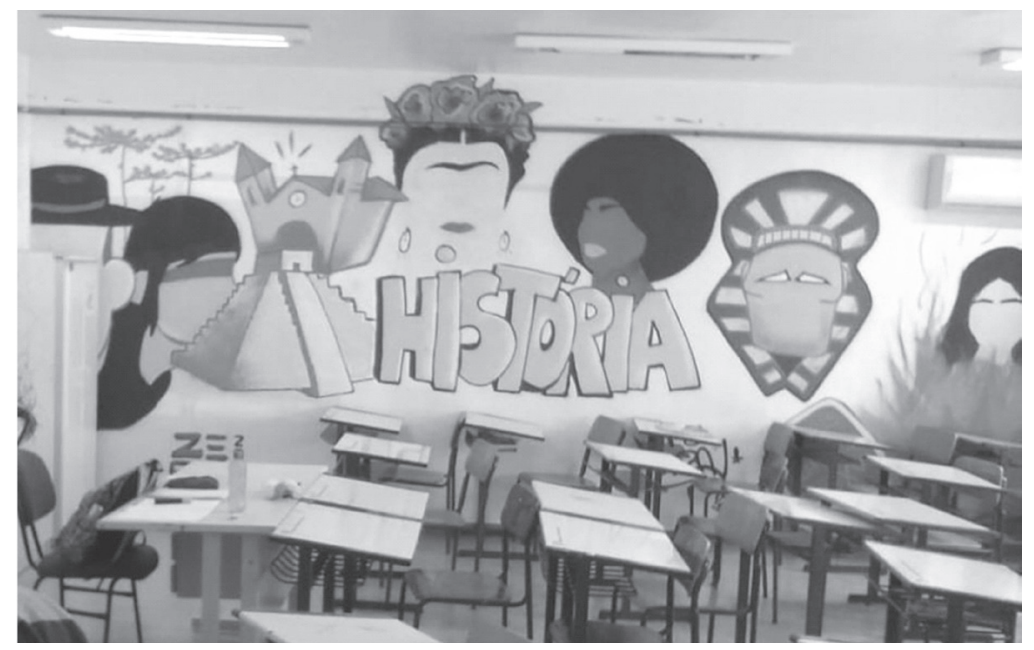

Figura 4 - Parede interna da sala de aula de História da E.E.B. Tancredo Neves

Fonte: Acervo pessoal de Izadora Parckert

Essa pintura busca representar um templo maia, uma múmia egípcia, uma representação indígena (não é possível perceber qual grupo étnico a figura representa), Frida Kahlo, um homem de indumentária gaúcha e uma bruxa queimando em uma fogueira. As pinturas foram feitas pelos bolsistas do Programa de Iniciação à Docência (PIBID) em 2017.

No entanto, apesar de não terem sido produzidas pelos próprios alunos, segundo as professoras, a partir do momento em que as paredes foram pintadas, eles passaram a cuidar melhor do espaço de sala de aula e diminuíram a frequência com que riscavam as mesas. Posto isso, podemos perceber que iniciativas como essas promovem uma melhor interação entre docente, aluno e escola. Além disso, a sala é equipada com um ar-condicionado, um projetor multimídia fixo, um computador e materiais de uso coletivo (fita, tesouras, grampeadores, etc.). 


\section{Reflexões Finais}

Partindo dessas breves considerações sobre o Programa de Residência Pedagógica, mais especificamente o núcleo de História da Universidade Federal da Fronteira Sul, podemos afirmar que a RP possibilitou um maior contato com as escolas, além de estabelecer uma relação mais próxima entre as escolas e a universidade. A possibilidade do acadêmico realizar todo seu estágio na mesma instituição, somado à presença de uma receptora que pode acompanhar o residente durante todo seu processo, além da possibilidade da realização dos estágios de forma remunerada (o que não ocorre com os acadêmicos que não participam da RP), só vem a qualificar e valorizar esse momento de formação dos futuros professores.

O contato com a unidade escolar permite tomar consideração dos problemas reais que a educação brasileira enfrenta, tal como vivenciam diariamente os discentes e docentes da educação básica, além de possibilitar uma inovação pedagógica. Para Leite, Genro e Braga (2011), inovação pedagógica está na capacidade de mobilizar e reconstruir, reorganizar a realidade, produzindo efeitos e rearranjos entre os saberes e os poderes. Uma inovação é pedagógica porque reconfigura ou favorece disputa entre saberes e poderes na sala de aula, porque convive e dá guarida às descontinuidades e incertezas do conhecimento, porque entra em conflito com os paradigmas tradicionais e acolhe o pensar e o fazer democrático (LEITE; GENRO; BRAGA, 2011, p. 38). Compreende-se que o envolvimento dos residentes nas escolas de educação básica contribui tanto para uma formação mais completa aos futuros docentes como beneficia as escolas que recebem esses alunos, uma vez que eles trazem consigo novos projetos e novas ideias. 
BRASIL. Lei n. 12.029, de 15 de setembro de 2009. Dispõe sobre a criação da Universidade Federal da Fronteira Sul (UFFS) e dá outras providências. [2009]. Disponível em: http://www.planalto.gov.br/ccivil_03/_ Ato2007-2010/2009/Lei/L12029.htm. Acesso em: 14 de out. 2019.

BRASIL. Lei n. 11.788, de 25 de setembro de 2008. Dispõe sobre o estágio de estudantes. [2008]. Disponível em: http://www.planalto.gov.br/ccivil_03/_ato2007-2010/2008/lei/11 1788.htm. Acesso em: 14 de out. 2019.

BRASIL. Decreto n. 6.096, de 24 de abril de 2007. Institui o Programa de Apoio a Planos de Reestruturação e Expansão das Universidades Federais (REUNI). Disponível em: http://www.planalto.gov. br/ccivil_03/_Ato2007-2010/2007/Decreto/D6096.htm. Acesso em: 14 de out. 2019.

BRASIL. CAPES - COORDENAÇÃO DE APERFEIÇOAMENTO DE PESSOAL DE NÍVEL SUPERIOR. Portaria Gab. n. 38, de 28 de fevereiro de 2018. Institui o Programa de Residência Pedagógica. [2018]. Disponível em: https://www.capes.gov.br/images/stories/download/legislacao/28022018-Portaria_n_38-Institui_RP.pdf. Acesso em: 14 de out. 2019.

DAL PIVA, Elisabete do Carmo. Ensino Médio Inovador: a vida política educacional em diálogo com a palavra das escolas de Santa Catarina. 2018. Dissertação (Mestrado) - Universidade Federal da Fronteira Sul, Chapecó, 2018.

DELGADO, Andréa Ferreira. Do currículo formal ao currículo em ação: o Estágio Supervisionado como experiência de pesquisa. In: SILVA, Cristiani Bereta da et al. (org.). Experiências de Ensino de História no Estágio Supervisionado. Florianópolis: Udesc, 2011. p. 221-245. 
E.E.B. CEL. ERNESTO BERTASO. Projeto Político Pedagógico (PPP). Chapecó, SC, 2017.

E.E.B. TANCREDO DE ALMEIDA NEVES. Projeto Político Pedagógico (PPP). Chapecó, SC, 2018.

IBGE - INSTITUTO BRASILEIRO DE GEOGRAFIA E ESTATÍSTICA. Censo Demográfico 2010. Rio de Janeiro: IBGE, 2010.

LEITE, D.; GENRO, M. E. H.; BRAGA, A. M. e S. Inovações pedagógicas e demandas ao docente na universidade. In: LEITE, D.; GENRO, M. E. H.; BRAGA, A. M. e S. (org.). Inovação e pedagogia universitária. Porto Alegre: UFRGS, 2011. p. 19-48.

MARTINS, Everton Bandeira. Estágio Supervisionado em Ensino de História: uma análise a partir das experiências em sala de aula conjugando teorias e prática. In: IX CONGRESSO NACIONAL DE EDUCAÇÃO - EDUCARE. 2009, Curitiba. Anais [...] Curitiba, 2009.

PIMENTA, Selma Garrido; LIMA, Maria Socorro Lucena. Estágio e docência: estágio - diferentes concepções. São Paulo: Cortez, 2004.

SILVA, Katia A. C. Pinheiro; CRUZ, Shirleide Pereira. A Residência Pedagógica na formação de professores: história, hegemonia e resistências. Momento: Diálogos em Educação, [S.l.], v. 27, n. 2, p. 227-247, maio/ago., 2018.

SCHMIDT, Maria Auxiliadora; CAINELLI, Marlene. Ensinar História. São Paulo: Scipione, 2004.

UFFS - UNIVERSIDADE FEDERAL DA FRONTEIRA SUL. Plano de Desenvolvimento Institucional (PDI) 2012-2018. Chapecó, SC: UFFS, 2012a.

UFFS - UNIVERSIDADE FEDERAL DA FRONTEIRA SUL. Projeto Pedagógico do Curso de Graduação em História - Licenciatura. Chapecó, SC: UFFS, 2012 b. 
